\title{
BMJ Open Prospective study of preoperative autologous blood donation for patients with high risk of allogeneic blood transfusion in lumbar fusion surgery: a study protocol of a randomised controlled trial
}

Nanfang Xu (D) , ${ }^{1,2,3}$ Youyu Zhang (D) , ${ }^{1}$ Yun Tian (D) , ${ }^{1}$ Baohua Li, ${ }^{4}$ Haiqin Qiao, ${ }^{4}$ Xiaoqing Zhang, ${ }^{5}$ Nan Yang, ${ }^{5}$ Wei Li, ${ }^{6}$ Chao Zhang, ${ }^{6}$ Weishi Li, ${ }^{1}$ Wei Fu (1) ${ }^{7}$

To cite: Xu N, Zhang Y, Tian Y, et al. Prospective study of preoperative autologous blood donation for patients with high risk of allogeneic blood transfusion in lumbar fusion surgery: a study protocol of a randomised controlled trial. BMJ Open 2022;12:e053846. doi:10.1136/ bmjopen-2021-053846

- Prepublication history for this paper is available online. To view these files, please visit the journal online (http://dx.doi org/10.1136/bmjopen-2021 053846).

$\mathrm{NX}$ and $\mathrm{YZ}$ contributed equally.

Received 25 May 2021

Accepted 08 December 2021

D Check for updates

(c) Author(s) (or their employer(s)) 2022. Re-use permitted under CC BY-NC. No commercial re-use. See rights and permissions. Published by BMJ.

For numbered affiliations see end of article.

Correspondence to

Dr Yun Tian; tiany@bjmu.edu.cn

\section{ABSTRACT}

Introduction Preoperative autologous blood donation (PABD) can be used to reduce the exposure of allogeneic blood transfusion in patients undergoing elective surgery. Better blood management to avoid anaemia and reduce allogeneic blood transfusion after spine surgery become increasingly important with development of enhanced recovery after surgery. We present here the design of a randomised controlled trial with three groups to verify the clinical effectiveness of PABD in patients at high risk of transfusion for lumbar fusion surgery and explore the optimal timing of autologous blood donation.

Method and analysis Patients (age 18-70 years) who will receive lumbar fusion surgery for degenerative disease with haemoglobin over $110 \mathrm{~g} / \mathrm{L}$ and 'high risk' of allogeneic blood transfusion are eligible, unless they refuse participation or are diagnosed with malignant metastases, infection, cardiovascular and cerebrovascular diseases, haematological disorders or relevant drug history and critical illnesses. A total of 1200 patients will be recruited and randomised into three groups. Patients in group $A$ will not receive $P A B D$ and be regarded as control group. $P A B D$ will be performed for patients in groups $B$ and $C$. Blood donation will be finished at 1 week ( \pm 3 day) before surgery in group B and 2 weeks ( \pm 3 day) before surgery in group C. Primary outcome measures will include haemoglobin decline, incidence and amount of allogeneic blood transfusion. Secondary outcome measures will include days of hospitalisation after surgery, haematocrit level and incidence of complications. This study is a single-centre and open-label randomised controlled trial. The sample size is calculated with reference to the retrospective data and previous studies.

Ethics and dissemination This trial has been approved by the Peking University Third Hospital Medical Science Research Ethic Committee (no: 2020-262-02). Results of the trial will be submitted for publication in a peerreviewed journal and as conference presentations. Trial registration number ChiCTR2000039824, preresults.

\section{Strengths and limitations of this study}

- This is a randomised controlled trial based on retrospective study with large sample size in recent years at the same centre.

- A validated risk score system will be implemented in the patient recruitment to ensure the necessity and validity of this trial.

- Participants and treating surgeons are not blinded to the intervention under evaluation.

\section{INTRODUCTION}

Preoperative autologous blood donation (PABD) can be used to reduce the exposure of allogeneic blood transfusion in patients undergoing elective surgery. ${ }^{12}$ Allogeneic blood transfusion is safe in our opinion currently but usually limited in clinical practice due to increasing blood shortage, ${ }^{3}$ and there are still inherent risks for allogeneic blood transfusion. ${ }^{4-6}$ Autologous blood transfusion techniques involve the collection and reinfusion of the patient's own blood with PABD being the common used form. ${ }^{7-9}$

Elective surgery in orthopaedics like spine or hip procedures is often associated with massive blood loss and high risk of anaemia after surgery. ${ }^{61011}$ Delayed wound healing and infection could be related to anaemia after surgery, and those are more susceptible and severe in orthopaedics due to the implant. Additionally, anaemia contributes to higher cardiac burden and may affect the functional exercise in the early postoperative period, which is essential for patients who underwent orthopaedic surgery. With the development of the concept of enhanced recovery 
after surgery in recent years, better blood management to avoid anaemia after surgery becomes increasingly important. In addition to an alternative in allogeneic blood shortage, ${ }^{12}$ there are also other advantages about PABD. It can be used for patients with rare blood groups, multiple allo-antibodies or religious objections to allogeneic transfusion. ${ }^{13}$ However, we should also be careful about this technique especially for the necessity, indication and cost-effectiveness in the clinical practice. ${ }^{14}$ PABD programme should be a multidisciplinary issue and based on a discussion between doctor and patient regarding the procedure's risks and benefits.

Surgical procedures with high risk of allogeneic blood transfusion should be considered for PABD. ${ }^{9}$ The less likely the transfusion, the more likely donated blood will not be used. Lumbar fusion surgery for patients with degenerative lumbar spine diseases often results in massive blood loss due to long time of operation, large wound and high difficulty to stop bleeding in the spinal canal area. All levels of anaemia were reported to be significantly associated with prolonged length of hospitalisation and poorer operative or 30-day outcomes in patients undergoing elective spine surgery. ${ }^{15}$ Blood management could be essential especially for patients with spine deformity and long segments fusion. Kennedy et al found that PABD was more efficient in patients who underwent instrumentation fusion but not all spine surgery. ${ }^{16}$ Solves et al also reported that PABD significantly decreased the allogeneic blood transfusion for spine instrumentation fusion in young patients. ${ }^{17}$ However, it is still controversial about the appliance and effectiveness of PABD in spine surgery. Brookfield et al reported that it is not beneficial for patients who underwent short lumbar spine fusion with normal blood coagulation. ${ }^{18}$ Cohort study by Kelly et al revealed that there is no protective effect of PABD against the risk of allogeneic blood transfusion for adult patients who underwent spine deformity surgery. ${ }^{19}$ Moreover, evidence about the timing of blood donation in PABD programme still remains insufficient. ${ }^{142}$ More evidence about the appliance and effectiveness of PABD in spine surgery is warranted.

In this randomised clinical trial, we aim to verify the clinical effectiveness of PABD in patients at high risk of allogeneic blood transfusion for lumbar fusion surgery with respect to the incidence and number of allogeneic blood transfusion, haemoglobin (Hgb) decline, days of hospitalisation after surgery, haematocrit level and incidence of complications. Study design of different time interval between blood donation and surgery help us to explore the optimal timing of autologous blood donation simultaneously.

\section{METHOD}

\section{Study design}

This study is planned to be a prospective and open-label randomised controlled trial with three groups (figure 1).

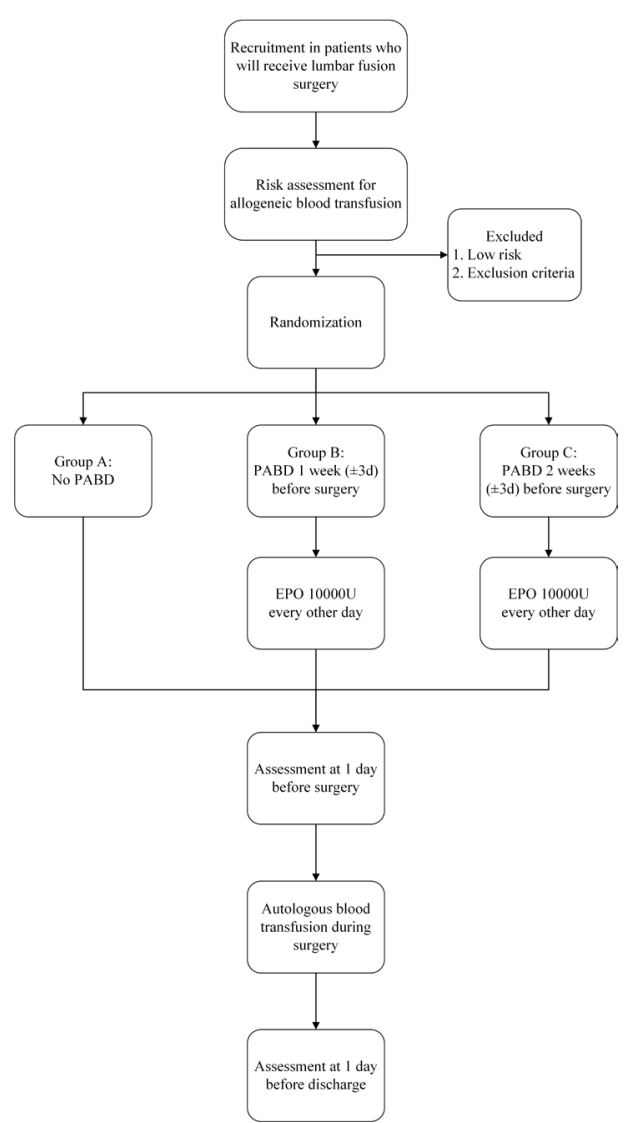

Figure 1 Study design. EPO, erythropoietin; PABD, preoperative autologous blood donation.

\section{Recruitment and informed consent}

This single-centre study will be conducted in the Peking University Third Hospital (PUTH). Eligible participants will be recruited from the patients who are going to receive lumbar fusion surgery in a 3 years period from 1 January 2022 to 31 December 2024 by our researchers. Recruitment, assessment and randomisation will be finished in the Inpatient Management Centre (IMC) that is in charge of preoperative evaluation before patients' admission. Researchers will discuss with eligible patients when they have decided to receive lumbar fusion surgery and then finish the informed consent. After enrolment, participants will be coded as a unique number and general information will be recorded.

\section{Eligibility}

\section{Inclusion criteria}

1. Patients who will receive elective lumbar fusion surgery for lumbar degenerative disease.

2. Age between 18 and 70 years.

3. Hgb over $110 \mathrm{~g} / \mathrm{L}$.

4. 'High risk' for the risk score of allogeneic blood transfusion for lumbar fusion surgery.

Exclusion criteria

1. Diagnosed with malignant metastases.

2. Infectious diseases. 
3. Cardiovascular and cerebrovascular diseases such as coronary heart disease and severe aortic stenosis.

4. Haematological disorders or drug history which are not suitable for blood donation.

5. Critically ill patients.

6. Refuse to participate for any reason.

\section{Randomisation}

Eligible participants recruited from the IMC in PUTH will be randomised to three groups via random number method by researcher who is blinded for outcome collection. Patients in group A will not receive PABD and be regarded as control group. PABD will be performed for patients in groups B and C. Blood donation will be finished at 1 week ( \pm 3 day) before surgery in group $B$ and 2 weeks ( \pm 3 day) before surgery in group C. Randomisation of the three groups will be on a 1:1:1 basis.

\section{Blinding}

Participants and surgeons will not be blinded to the interventions. As the PABD plans should be informed to patients clearly. The assessment after surgery will be performed by research assistants who are blinded to the recruitment and randomisation.

\section{Interventions}

\section{Blood donation and transfusion}

All eligible participants will be randomised to three groups after preoperative evaluation. Participants in group A will not receive PABD and regarded as control group. Donation of $400 \mathrm{~mL}$ autologous blood will be finished once at 1 week ( \pm 3 day) before surgery for participants in group B and 2 weeks ( \pm 3 day) before surgery for group C. We also allow participants to finish the donation 3 days before or after the time points in consideration of the feasibility in practice. All donated blood in our study will be transfused back during surgery unless the Hgb level is still above $125 \mathrm{~g} / \mathrm{L}$ for man and $115 \mathrm{~g} / \mathrm{L}$ for woman before wound closure, then the autologous blood will not be transfused and be stored until the discharge of patients. Tranexamic acid and intraoperative blood salvage will be applied in three groups as usual. Autologous blood donation, preservation at $2-6^{\circ} \mathrm{C}$ in dedicated refrigerator and transfusion during surgery will be assisted and finished by department of Blood Transfusion and Anesthesiology. Patients in groups $\mathrm{B}$ and $\mathrm{C}$ will be given subcutaneous injection of 10 000U erythropoietin (EPO) every other day (quaque altera die (qod)) until the date of surgery. Time schedule of interventions can be followed in table 1 .

\section{Assessment and management}

We have established a risk score of allogeneic blood transfusion for lumbar fusion surgery in the preliminary study. This score system consist of six parameters including age, body mass index, number of fusion and fixation segments, spine deformity and Hgb level (table 2). The risk score of allogeneic blood transfusion for lumbar fusion surgery was established based on the retrospective data of 5101 cases of lumbar spine surgery in the past 2 years from
Table 1 Time schedule of interventions

1-2 weeks

before

\begin{tabular}{llll} 
Interventions & Admission & surgery & Perioperation \\
\hline $\begin{array}{l}\text { Preoperative } \\
\text { evaluation }\end{array}$ & $\sqrt{ }$ & \\
$\begin{array}{l}\text { Blood donation } \\
\text { EPO injection }\end{array}$ & $\sqrt{ }$ & \\
$\begin{array}{l}\text { Autologous } \\
\text { blood }\end{array}$ & $\sqrt{ }$ & \\
transfusion & & & \\
\end{tabular}

EPO, erythropoietin; .

2018 to 2019 . We have performed preliminary validation for the risk score system in the patients from January to June 2020 prospectively. The effectiveness was acceptable with sensitivity of $76 \%$ (area under curve, AUC=0.83).

All participants will be assessed at outpatient and IMC, including demographic information, height and weight, blood test and radiographic examination. Spine surgeons

Table 2 Risk score of allogeneic blood transfusion for lumbar fusion surgery

\begin{tabular}{|c|c|}
\hline Characteristic & Score \\
\hline \multicolumn{2}{|l|}{ Age } \\
\hline$<60$ years & 0 \\
\hline$\geq 60$ years & 1 \\
\hline \multicolumn{2}{|l|}{$\mathrm{BMI}$} \\
\hline$\geq 18.5$ & 0 \\
\hline$<18.5$ & 1 \\
\hline \multicolumn{2}{|c|}{ No. of fusion segments } \\
\hline 1 & 1 \\
\hline 2 & 2 \\
\hline 3 & 3 \\
\hline$\geq 4$ & 4 \\
\hline \multicolumn{2}{|c|}{ No. of fixation segments } \\
\hline 2 & 1 \\
\hline 3 & 2 \\
\hline 4 & 3 \\
\hline$\geq 5$ & 4 \\
\hline \multicolumn{2}{|l|}{ Spine deformity } \\
\hline No & 0 \\
\hline Yes & 1 \\
\hline \multicolumn{2}{|c|}{ Haemoglobin (g/L) } \\
\hline$\geq 140$ & 0 \\
\hline $125-140$ & 1 \\
\hline$<125$ & 2 \\
\hline
\end{tabular}

Total score 0-4=low risk; total score 5-13=high risk. BMI, body mass index. 
will make a general surgical plan including fusion and fixation segments. Patients with low risk of allogeneic blood transfusion will be excluded from our study. Baseline iron metabolism and vitamin will be screened for all participants. Oral iron supplements and vitamin drugs will be initialled and continued until the day before surgery for patients with iron and vitamin deficiencies. All patients will receive one unit of allogenic blood transfusion if their Hgb level drop below $8.0 \mathrm{~g} / \mathrm{dL}$ and the patient display clinical symptom of anaemia (tachycardia and/or hypotension) despite intravenous fluid boluses.

\section{Outcome measurements}

Primary outcome

\section{Incidence of allogeneic blood transfusion}

Intraoperative or postoperative allogeneic blood transfusion will be recorded as binary outcome. Incidence of allogeneic blood transfusion will be statistically compared as primary outcome.

\section{Amount of allogeneic blood transfusion}

Total number $(\mathrm{mL})$ of allogeneic blood transfusion for each patient in three groups will be recorded as continuous outcome and analysed as the primary outcome.

\section{Hgb decline}

Hgb decline (g/L) from 1 day before surgery to 1 day before discharge will be recorded as continuous outcome and analysed as one of the primary outcomes.

\section{Secondary outcome}

\section{Days of hospitalisation after surgery}

Length of hospitalisation after surgery could be an indicator for recovery and will be recorded as continuous outcome in this study. Days of hospitalisation after surgery will be compared and statistically analysed as secondary outcome.

\section{Haematocrit level}

Haematocrit check will be scheduled weekly for patients in groups B and C. Preoperative haematocrit level will be assessed in group A regularly. Initial and preoperative haematocrit level will be compared between two groups receiving EPO administration and recorded as secondary outcome.

\section{Incidence of complications}

Wound infection and complications associated with blood transfusion will be recorded as binary outcome and analysed as secondary outcome.

\section{Data management}

Each patient will receive a unique number and all data will be recorded with this number. An attending spine surgeon and a research assistant will be in charge of the examination and assessment in the perioperative period. Research assistant will maintain the follow-up 1 month after surgery. Data entry and transfer will be performed by two staff and two computers. All data including baseline information, risk score, Hgb result, allogeneic blood transfusion and ability assessments will be secured in PUTH and the access will be restricted to the research team. Database will be established after finishing all the data collection and back-ups will be made in multiple disks. All raw data will be kept in the Medical record department.

\section{Patient and public involvement}

Patients or public were not involved in the design, conduct, reporting or dissemination plans of our research.

\section{Safety monitoring and adverse events}

Participants in this study will receive PABD before lumbar spine surgery. All participants will be observed for $40 \mathrm{~min}$ after blood donation. Patients with Hgb less than $110 \mathrm{~g} / \mathrm{L}$, infectious diseases, cardiovascular or cerebrovascular diseases will be excluded from our study in consideration of safety. Strictly standard collection and storage processes will be performed and monitored by department of IMC and Blood Transfusion. All expected or unexpected adverse events from this study will be recorded and monitored. Patients suffered from any adverse events related to the interventions in research will receive free treatment.

\section{Sample size calculation}

There were 5101 cases of lumbar fusion surgery from January 2018 to November 2019 and 817 cases received allogeneic blood transfusion. The incidence of allogeneic blood transfusion was $16 \%$. The preliminary study of PABD from August 2020 to September 2020 demonstrated that the incidence of allogeneic blood transfusion decreased by $18 \%$ compared with the same time period in 2019. We hypothesise that the incidence of allogeneic blood transfusion decreased by $18 \%$ via PABD for patients at high risk score for lumbar fusion surgery. We should recruit 400 patients for both groups PABD and non-PABD. This is based on $\alpha$ at 0.025 and power at $80 \%$ considering a 1:1 allocation rate and accuracy rate of $80 \%$ for risk score system. On the other hand, a single injection of EPO was reported to result in Hgb increase of $2.9 \mathrm{~g} / \mathrm{L}$ in adolescence. ${ }^{21}$ We hypothesise that a single injection of EPO could attain Hgb increase of $2.5 \mathrm{~g} / \mathrm{L}$ in adults who are going to receive lumbar fusion surgery, the Hgb level in group C before surgery should be $10 \mathrm{~g} / \mathrm{L}$ more than patients in group B and we assume to be 120 $\mathrm{g} / \mathrm{L}$ and $110 \mathrm{~g} / \mathrm{L}$, respectively. Then we should recruit 330 patients for both groups B and C. This is based on $\alpha$ at 0.025 and power at $80 \%$ considering a $1: 1$ allocation rate. To sum up, we will recruit a total of 1200 patients for three groups.

\section{Statistical analysis}

The baseline characteristics of all participants will be summarised by group and presented as means (SD) for continuous variables, and count (\%) for categorial variables. All the confounding variables which may influence the primary outcome will be recorded and compared among three groups. Incidence of allogeneic 
blood transfusion and complications will be measured as binary outcome. Amount of allogeneic blood transfusion $(\mathrm{mL})$, Hgb decline, days of hospitalisation after surgery and haematocrit level will be measured as continuous outcome. $\chi^{2}$ test and logistical regression will be used for the binary outcome. Non-parametric test or t test will be performed for continuous outcome according to the distribution. A value of $\mathrm{p}<0.05$ will be considered as statistically significant. All analysis will be performed using SPSS V.17.0 by a researcher who is blinded to recruitment and data collection.

\section{Ethic and dissemination}

This trial has been approved by the PUTH Medical Science Research Ethic Committee (no.: 2020-262-02) and registered on Chictr.org (registration number: ChiCTR2000039824). Informed consent will be obtained for all participants. Results of the trial will be submitted for publication in a peer-reviewed journal and as conference presentations.

\section{DISCUSSION}

We have presented the rationale and design of a prospective randomised controlled trial to compare the outcomes of PABD in patients at high risk of allogeneic blood transfusion for lumbar fusion surgery. The randomised controlled trial (RCT) will compare the outcome among three groups to verify the clinical effectiveness of PABD and explore the optimal timing of blood donation with adjuvant EPO injection in lumbar fusion surgery.

In the previous studies of PABD, the time interval between first blood donation and surgery varied from less than 2 weeks to more than 4 weeks. ${ }^{142}$ Adequate time interval was thought to be crucial for the red blood cell (RBC) regeneration of donated blood. ${ }^{22}$ But it should also be noted that there is an outdate for the donated blood in plastic bags. An appropriate time interval to balance the regeneration and preservation of donated blood is significant for the efficiency of PABD programme. We choose an interval of 1-2 weeks to reduce the storage time of donated blood in autologous blood bank. Meanwhile, adjuvant EPO injection after blood donation will be used for all patients in groups $\mathrm{B}$ and $\mathrm{C}$ to accelerate the RBC regeneration. EPO injection was reported to be useful for increasing the RBC before hip surgery and avoiding allogeneic transfusion during spinal deformity surgery in PABD programme. ${ }^{2123}$ To explore the optimal timing of autologous blood donation with EPO injection is also one of the main goals in this prospective study.

In this study, a validated risk score system of allogeneic blood transfusion for lumbar fusion surgery based on retrospective study with large sample size will be implemented to ensure the necessity for PABD programme. Both this technique and EPO injection should be more efficient in the patients with higher risk of blood transfusion. ${ }^{20}{ }^{24}$ Waste of donated blood was an inherent risk for PABD programme. ${ }^{25} 26$ The review by Singbartl reported that the wastage of unneeded PABD units varied from $18 \%$ to above $50 \% .{ }^{27}$ All donated blood in our study will be storage for a relatively shorter time period and transfused back during operation unless the Hgb level is still above $125 \mathrm{~g} / \mathrm{L}$ for man and $115 \mathrm{~g} / \mathrm{L}$ for woman before wound closure, then the autologous blood will not be transfused and be storage until the discharge of patients. This design aims to eliminate the waste of donated blood and simultaneously decrease the risk of allogeneic blood transfusion in perioperative period for targeted patients who will receive lumbar fusion surgery. A multidisciplinary cooperation including department of IMC, Blood Transfusion, Anesthesiology and Orthopedics in the hospital will ensure the safety and feasibility of this prospective trial in clinical practice.

\section{Author affiliations}

${ }^{1}$ Department of Orthopaedics, Peking University Third Hospital, Beijing, China ${ }^{2}$ Engineering Research Center of Bone and Joint Precision Medicine, Ministry of Education, Beijing, People's Republic of China

${ }^{3}$ Beijing Key Laboratory of Spinal Disease Research, Beijing, People's Republic of China

${ }^{4}$ Department of Inpatient Management Center, Peking University Third Hospital, Beijing, China

${ }^{5}$ Department of Blood Transfusion, Peking University Third Hospital, Beijing, China ${ }^{6}$ Information Management and Big Data Center, Peking University Third Hospital, Beijing, China

${ }^{7}$ Department of General Surgery, Peking University Third Hospital, Beijing, China

Contributors NX and YZ contributed to design the trial and drafted the manuscript. YT contributed to design the trial and oversaw the manuscript writing and submission. All authors contributed to the trial design and have read and approved this manuscript.

Funding This trial is funded by Peking University Third Hospital Clinical Research Development Program (BYSYFY2021036 and BYSYZD2021009).

Competing interests None declared.

Patient and public involvement Patients and/or the public were not involved in the design, or conduct, or reporting, or dissemination plans of this research.

Patient consent for publication Not applicable.

Provenance and peer review Not commissioned; externally peer reviewed.

Open access This is an open access article distributed in accordance with the Creative Commons Attribution Non Commercial (CC BY-NC 4.0) license, which permits others to distribute, remix, adapt, build upon this work non-commercially, and license their derivative works on different terms, provided the original work is properly cited, appropriate credit is given, any changes made indicated, and the use is non-commercial. See: http://creativecommons.org/licenses/by-nc/4.0/.

\section{ORCID iDs}

Nanfang Xu http://orcid.org/0000-0001-5888-293X

Youyu Zhang http://orcid.org/0000-0001-5606-620X

Yun Tian http://orcid.org/0000-0003-2310-6054

Wei Fu http://orcid.org/0000-0001-5248-7891

\section{REFERENCES}

1 Goodnough LT. Autologous blood donation. Anesthesiol Clin North Am 2005;23:263-70. vi.

2 Pawaskar A, Salunke AA, Kekatpure A, et al. Do autologous blood transfusion systems reduce allogeneic blood transfusion in total knee arthroplasty? Knee Surg Sports Traumatol Arthrosc 2017;25:2957-66.

3 Yu X, Wang Z, Shen Y, et al. Population-based projections of blood supply and demand, China, 2017-2036. Bull World Health Organ 2020;98:10-18. 
4 Kato S, Chikuda H, Ohya J, et al. Risk of infectious complications associated with blood transfusion in elective spinal surgery-a propensity score matched analysis. Spine J 2016;16:55-60.

5 Owens RK, Crawford CH, Djurasovic M, et al. Predictive factors for the use of autologous cell saver transfusion in lumbar spinal surgery. Spine 2013;38:E217-22.

6 Friedman R, Homering M, Holberg G, et al. Allogeneic blood transfusions and postoperative infections after total hip or knee arthroplasty. J Bone Joint Surg Am 2014;96:272-8.

7 García-Erce JA, Muñoz M, Bisbe E, et al. Predeposit autologous donation in spinal surgery: a multicentre study. Eur Spine J 2004;13 Suppl 1:S34-9.

8 Cha CW, Deible C, Muzzonigro T, et al. Allogeneic transfusion requirements after autologous donations in posterior lumbar surgeries. Spine 2002;27:99-104.

9 Anon. Transfusion alert: use of autologous blood. National heart, lung, and blood Institute expert panel on the use of autologous blood. Transfusion 1995;35:703-11.

10 Wen L, Jin D, Xie W, et al. Hidden blood loss in posterior lumbar fusion surgery: an analysis of risk factors. Clin Spine Surg 2018;31:180-4.

11 Lasocki S, Krauspe R, von Heymann C, et al. Prepare: the prevalence of perioperative anaemia and need for patient blood management in elective orthopaedic surgery: a multicentre, observational study. Eur $J$ Anaesthesiol 2015;32:160-7.

12 Goodnough LT, Marcus RE. Effect of autologous blood donation in patients undergoing elective spine surgery. Spine 1992;17:172-5.

13 Ridgeway S, Tai C, Alton P, et al. Pre-donated autologous blood transfusion in scoliosis surgery. J Bone Joint Surg $\mathrm{Br}$ 2003;85:1032-6.

14 Vassallo R, Goldman M, Germain M, et al. Preoperative autologous blood donation: waning indications in an era of improved blood safety. Transfus Med Rev 2015;29:268-75.

15 Seicean A, Seicean S, Alan N, et al. Preoperative anemia and perioperative outcomes in patients who undergo elective spine surgery. Spine 2013;38:1331-41.
16 Kennedy C, Leonard M, Devitt A, et al. Efficacy of preoperative autologous blood donation for elective posterior lumbar spinal surgery. Spine 2011;36:E1736-43.

17 Solves P, Carpio N, Moscardo F, et al. Results of a preoperative autologous blood donation program for patients undergoing elective major spine surgery. Transfus Apher Sci 2013;49:345-8.

18 Brookfield KF, Brown MD, Henriques SM, et al. Allogeneic transfusion after predonation of blood for elective spine surgery. Clin Orthop Relat Res 2008;466:1949-53.

19 Kelly MP, Zebala LP, Kim HJ, et al. Effectiveness of preoperative autologous blood donation for protection against allogeneic blood exposure in adult spinal deformity surgeries: a propensity-matched cohort analysis. J Neurosurg Spine 2016;24:124-30.

20 Singbartl G. Preoperative autologous blood donation - part I. Only two clinical parameters determine efficacy of the autologous predeposit. Minerva Anestesiol 2007;73:143-51.

21 Ikegami S, Takahashi J, Kuraishi S, et al. Efficacy of ErythropoietinBeta injections during autologous blood donation before spinal deformity surgery in children and teenagers. Spine 2015;40:E1144-9.

22 Pottgiesser T, Specker W, Umhau M, et al. Recovery of hemoglobin mass after blood donation. Transfusion 2008;48:1390-7.

23 Vargas-Pabon M, Diaz-Trapiella A, Hurtado MJ, et al. Erythropoietin as adjuvant to pre-operative autologous blood donation in total hip arthroplasty: new algorithm for use. Transfus Apher Sci 2005;33:91-7.

24 Bou Monsef J, Figgie MP, Mayman D, et al. Targeted pre-operative autologous blood donation: a prospective study of two thousand and three hundred and fifty total hip arthroplasties. Int Orthop 2014;38:1591-5.

25 Hatzidakis AM, Mendlick RM, McKillip T, et al. Preoperative autologous donation for total joint arthroplasty. An analysis of risk factors for allogenic transfusion. J Bone Joint Surg Am 2000;82:89-100.

26 Parvizi J, Chaudhry S, Rasouli MR, et al. Who needs autologous blood donation in joint replacement? J Knee Surg 2011;24:025-32.

27 Singbartl G. Pre-Operative autologous blood donation: clinical parameters and efficacy. Blood Transfus 2011;9:10-18. 